\title{
Toward an understanding of state behavior in prolonged international negotiations
}

\section{Contact Details:}

Dr Christian Downie

Regulatory Institutions Network (RegNet)

School of Regulation, Justice and Diplomacy College of Asia and Pacific

Australian National University

Canberra, ACT 0200

Australia

P: +61261256569

F: +61 261257789

Email: christian.downie@anu.edu.au

\begin{abstract}
Many of the most significant international treaty negotiations take years, and sometimes decades, to conclude. The international climate negotiations, trade negotiations and law of the sea negotiations are all examples. Yet notwithstanding their commonality and importance, prolonged international negotiations are not well understood. In these negotiations, state preferences are fluid not fixed, as negotiating positions change. This temporal dimension of prolonged negotiations is insufficiently captured by existing theories of international negotiations, which, by virtue of their focus on individual negotiation outcomes at one point in time, tend to be static in their analysis.

This article combines an analysis of existing theories of international negotiations with the findings of an empirical study of the climate change negotiations. In doing so, it reveals a series of internal and external factors distinctive to prolonged international negotiations, emphasises the importance of the temporal dimension, and explains how and why the negotiating positions and the type of agreements states are prepared to sign changes over time. Building on these variables, it is argued that state behaviour in prolonged international negotiations can be usefully conceived of as (at different points in time) either an immature or mature game, in which strategic opportunities arise at different phases of the game for networked actors to constructively influence state behaviour. Eight strategies are suggested that traditionally weak actors can employ to steer prolonged international negotiations toward their preferred outcome.
\end{abstract}

\section{Keywords:}

International negotiations theory, state actors, non-state actors, climate change. 


\section{Introduction}

Many international negotiations, particularly in the post-war era, have been prolonged, stretching for years and sometimes decades. This has certainly been true for environmental and trade issues. The international negotiations on the Law of the Sea and the Uruguay Round of trade negotiations both lasted almost a decade and the most recent Doha Round of trade negotiations will surpass them both. The international climate negotiations represent one of the best examples of this phenomenon. In fact, the so-called "Kyoto phase" of climate negotiations which commenced with the first Conference of the Parties to the United Nations Framework Convention on Climate Change (UNFCCC) in 1995 and took a decade to conclude before the Kyoto Protocol ultimately entered into force.

Although prolonged international negotiations, such as the climate negotiations, seek to address some of the most critical problems facing the globe, the phenomenon is not well understood. Most of the literature on international negotiations has been concerned with explaining why states cooperate: with how and why international negotiations succeed or fail. Yet remarkably almost none of this work has considered whether these questions lead to different answers when negotiations stretch out for years. While great strides have been made in understanding the negotiation process or the larger context surrounding the negotiation (see for example, Susskind \& Crump 2008: Vol. 4), theorising has not considered these factors when negotiations become protracted. For example, extensive work has been done on the role of state and non-state actors in international negotiations, on the influence of domestic pressures and domestic political institutions (Putnam 1988, Moravcsik 1993), on the role of transnational activities of state and non-state actors (Keohane \& Nye 1972, Keohane \& Nye 1974, Risse-Kappen 1995a, Milner \& Moravcsik 2009) and on the impact of international regimes (Krasner 1983, Levy et al. 1995, Young 1999, Young 2011). Yet very little work has been undertaken on how these factors vary over time in drawn-out negotiations.

The temporal dimension of prolonged international negotiations matters because it draws our attention to variables, strategies and outcomes that are not apparent if the focus is on individual negotiation outcomes. This has implications for negotiation theory and practice.

First, by considering the temporal dimension it is clear that the preferences of actors, including states, are fluid not fixed, and that their preferences are influenced by a variety of variables, including different levels of engagement of actors, the preferences of chiefs of 
government and the changing state of expert knowledge among policy elites. Second, because preferences are fluid in long negotiations actors, including traditionally weak actors, have considerable agency to influence state behaviour. As a result, there are strategic opportunities in the course of a protracted negotiation for actors to steer negotiations toward their preferred outcomes. Third, the type of agreement possible and the likelihood that an agreement will be reached will also be contingent on the stage of the negotiations. Different agreements and different outcomes will be more likely at different points in the course of a long negotiation.

This paper attempts to show the importance of considering these aspects by developing an "ideal type" framework as a first step toward understanding the temporal dimension of prolonged international negotiations. To do so the paper proceeds in five parts; the next section provides a theoretical background to the concept of prolonged international negotiations. Section three combines an analysis of existing theories with the findings of a large empirical study of state behaviour in the protracted international climate negotiations to identify 'internal' and 'external' factors that explain why the preferences of states change. Section four uses these variables as a basis for considering prolonged international negotiations. The aim is not to develop a formal model in a game-theoretic sense, nor even to provide a model with testable if-then propositions. Rather the aim is to sketch out an 'ideal type' framework to improve our understanding of prolonged negotiations. Having done so, section five is able to identify strategies that state and non-state actors can use to influence state behaviour.

\section{Theoretical background: what do we mean by prolonged international negotiations?}

\section{Theoretical background}

Theorizing about international relations has been dominated by state centered approaches. For realists, neo-realists, liberals and even constructivists, the state is viewed as the primary actor in an international system characterized by anarchy (Lake 2008). However, as scholars have observed the growing complexity of world politics and its manifestation in international negotiations (Crump \& Zartman 2003), increasingly terms such as "governance" and "networks" are used to capture the complex interdependencies between different types of actors at different levels, be it the domestic, international or transnational level, which invariably shape international outcomes (Rosenau 2000, 2007, Hafner-Burton et al. 2009, Lake 2010). 
One line of inquiry has been to relax the common assumption of the state as a unitary actor to account for domestic politics in international negotiations (Lake 2008). The most influential framework is Robert Putnam's “two-level game” (Putnam 1988). Putnam argued that at the national level (Level II), domestic groups pressure their governments to adopt policies they support, while governments seek power by engineering coalitions among their national constituents. At the international level (Level I), governments want to satisfy domestic pressures, while limiting any negative consequences from foreign developments.

In the two-level framework put forward by Putnam the chiefs of government (COGs) monopolize the external representation of the state, but in contrast to the unitary actor model they are constrained by domestic political dynamics. In opening the black box of domestic politics, Putnam argued that the size of the "win-set", that is, the set of all possible international agreements that would be acceptable domestically, is a key determinant for understanding the success or failure of an international negotiation. For example, he was concerned with the preferences of domestic actors, the distribution of domestic coalitions and the structure of domestic political institutions, yet he also argued that despite such domestic constraints COGs can use their privileged position at both tables to manipulate their own winset and that of other nations: "clever players will spot a move on one board that will trigger realignments on other boards, enabling them to achieve otherwise unattainable objectives" (Putnam 1988:434).

From this perspective the state is no longer conceived as a unitary actor. State and non-state actors at the domestic level affect the ability of negotiators at the international level to reach an agreement that can be ratified. However, the COG monopolizes the external representation of the state because they aggregate and manipulate the preferences of domestic actors that remain contained at the domestic level. A second line of inquiry, the transnational perspective takes a different view. Scholars in this tradition argue that "transnational relations matter in world politics" and that state behavior in international relations cannot be understood without taking account of the cross-boundary activities of sub-units of government and non-state actors (Risse-Kappen 1995b: 280). In this view, even though the two-level game disaggregates the state, it is too narrow because it implies limited access to the international 
system, which "no longer holds true in many issue areas" (Keck \& Sikkink 1998: 4). ${ }^{1}$ In other words, we must look inside and outside state borders.

This perspective has highlighted the role of transnational networks, that is, "regular interactions across national boundaries when at least one actor is a non-state agent or does not operate on behalf of a national government or an intergovernmental organization" (RisseKappen 1995a). One of the most influential attempts to analyze effectiveness of transnational actors was Peter Haas' pioneering work on epistemic communities. That is, a "network of professionals with recognized expertise and competences in a particular domain and an authoritative claim to policy-relevant knowledge within that domain or issue-area" (Haas 1992: 3). Haas argued that the language of science is becoming a worldview that penetrates politics everywhere and hence could affect how states' interests are defined. ${ }^{2}$

A third line of inquiry has highlighted the importance of international regimes, which refer to "principles, norms, rules, and decision-making procedures around which actor expectations converge in a given issue-area" (Krasner 1983: 1). In order to demonstrate that regimes matter and can potentially impact international political interactions like international negotiations, scholars from this line of inquiry have emphasized regime formation (Breitmeier et al. 2006, Hasenclever et al. 2000, Levy et al. 1995). Others have looked at regime effectiveness. For example, in their analysis of international environmental regimes, Young and Levy (1999) suggest a series of utilitarian and non-utilitarian pathways by which regimes can affect actor behavior.

It is important to be mindful of the overlap between these lines of inquiry. First, the interaction between the domestic and international levels in the two-level framework cannot be understood in the absence of international regimes. International regimes help to constitute the two-level game; the interaction between both levels would prove mighty difficult in the absence of some basic rules and norms which international regimes provide. Likewise, transnational networks of state and non-state actors must be conceived in the context of international regimes. Transnational networks almost rarely form without international

\footnotetext{
${ }^{1}$ This has been acknowledged in the subsequent literature, which expanded on Puntam's two-level game. See for example, (Moravcsik 1993).

${ }^{2}$ The empirical inquiries of Haas and others showed that the involvement of epistemic communities can promote organizational learning by helping to create shared understandings in their specialised field and hence to improve state cooperation (Haas 1989, Haas 1992, Braithwaite \& Drahos 2000, Ruggie et al. 2005, Raustiala \& Bridgeman 2007).
} 
regimes, and at the same time such networks contribute to the definition of international regimes themselves.

In summary, while these lines of inquiry capture the main factors that are commonly used to explain outcomes in international negotiations, stepping back we can see that it is not clear how domestic political dynamics, transnational actors and international regimes affect state behavior over time. In other words, these frameworks look only at the end game, at one specific negotiation outcome. For example, the two-level perspective is valuable for understanding how domestic politics and international relations interact in a one-off negotiation. But, if one is to inquire into how domestic political dynamics change to affect international outcomes in long negotiations, the two-level approach is limited. This is because it ignores the temporal dimension. In focusing on the end game it looks only at the role of actors at a point in time.

\section{Prolonged international negotiations}

In order to capture the temporal dimension of long negotiations, it is necessary to elaborate more definitively what we mean by prolonged international negotiations. While much of the negotiation literature has been concerned with one-off negotiations, scholars have sought to elaborate on how negotiations evolve through time. Indeed, this paper is not the first to note that international negotiations are not static and nor are the problems they seek to resolve (Spector \& Zartman 2003, Daugberg \& Swinbank 2009, Enia 2009).

In noting that negotiations evolve, scholars in the negotiation tradition have been largely interested in identifying different phases in negotiations. While there is much overlap in the literature, two sets of phases can be broadly identified; pre-agreement phases and postagreement phases. Pre-agreement phases can be said to include those phases first identified by Zartman and Berman (1982). First, the diagnostic phase preludes when the parties formally sit down at the negotiating table. In essence, "it is the span of time and activity in which the parties move from conflicting unilateral solutions for a mutual problem to a joint search for cooperative multilateral or joint solutions" (Zartman 1989: 240). Second, is the formula phase, a period of "intensive negotiations" in which parties commonly establish a formula that "provides a substantive framework for agreement and a set of criteria for resolving details" (Zartman \& Berman 1982:143). In the third phase, the detail phase, the 
parties send signals to each other, exchange points, arrange details, and attempt to bring the negotiations to an end using deadlines.

Post-agreement phases, on the other hand, refer to the negotiations that take place after an agreement has been reached over the terms and obligations of international treaties. Spector (2003) identifies three domestic and three international processes that make up the postagreement phase. Domestically he points to; ratification negotiations, which are required to achieve formal acceptance of the agreement, rule-making negotiations, which are required to implement the agreement at the national level, and negotiations concerning monitoring, reporting and enforcement to provide feedback to the international regime. Internationally, he identifies three parallel processes; regime formation negotiations over the agreed-upon rules and procedures, regime governance negotiations concerning monitoring, reporting and verification, and finally, regime adjustment negotiations. Of course, each of these phases are not necessarily sequential and many overlap (Spector 2003, Jonsson \& Tallberg 1998). ${ }^{3}$

What then, do we mean by prolonged international negotiations? Prolonged international negotiations are defined here as substantive international negotiations over a legally binding instrument that continue for five or more years, which begin with bargaining over a tentative agreement and conclude with bargaining over the ratification of that instrument. Because this definition refers to substantive negotiations over a legal instrument it can therefore include the negotiation of consecutive non-binding agreements on the path towards a legal instrument, either in a bilateral or a multilateral negotiation. In addition, five or more years is considered a prolonged period because of the natural variations that occur over this period via political and economic cycles, such as a change in government or an economic downturn, which produce ripple effects.

Further, much like the literature on the two-level game, this definition assumes a bargaining phase and a ratification phase, which provides the "crucial theoretical link" between domestic and international politics (Moravcsik 1993: 23). The bargaining phase refers to the negotiations that set out the framework for an agreement and proceed to flesh out the details of such an agreement for adoption whereas, the ratification phase refers to the negotiations that take place after an agreement has been reached but before it enters into force. This

\footnotetext{
${ }^{3}$ Other theorists have applied these concepts to study environmental negotiations and trade negotiations, among others, and to identify critical turning points as negotiations move from phase to phase (Chasek 1997, Chasek 2001, Druckman 2001, Smith 2006, Smith \& Tallberg 2005).
} 
definition then does not include what Zartman referred to as the prenegotiation phase, which preludes when the parties formally sit down at the negotiating table. Nor does it include those negotiations that Spector described which take place after the ratification negotiations at the domestic level and the regime formation negotiations at the international level. In other words, substantive prolonged international negotiations do not include the ongoing monitoring, reporting, verification and enforcement processes, which proceed for years, and often decades, as the parties meet to review the implementation of a treaty.

To illustrate, the international climate change negotiations that took place between 1995 and 2005 can be considered a substantive round of prolonged negotiations. The first Conference of the Parties (COP) to the UNFCCC held in Berlin in 1995 can be considered the start of the so-called "Kyoto phase" of negotiations because it is here that parties began negotiating a tentative international treaty. After the Kyoto Protocol was agreed to at COP 3 in Japan in 1997, the ratification phase took place, which concluded with COP 11 in Montreal in 2005 after Russia ratified the Protocol and it entered into force. In other words, this was the period of the substantive negotiations and not those negotiations which followed to review the implementation of the treaty. In contrast, the international negotiations on the ozone layer could not be considered a prolonged international negotiation because of the speed with which the substantive negotiations concluded. In fact, the negotiations for the Montreal Protocol, which commenced in 1986 with bargaining over a tentative protocol, were concluded less than 3 years later when the Protocol entered into force in 1989 (Benedick 1991).

The international climate change negotiations also highlight how state preferences vary over the course of a prolonged international negotiation. Take the cases of the US and the EU, two of the most important parties, during the Kyoto phase of the climate negotiations. In both cases their negotiating positions changed as did the type of agreement that they were prepared to sign. In 1995 the US and the EU agreed to the Berlin Mandate, which stipulated no binding emissions targets for developed countries, no new commitments for developing countries and no flexibility mechanisms (emissions trading). Then in 1997, the US and the EU agreed to the Kyoto Protocol, which included binding emissions targets for developed countries and 
flexibility mechanisms. Yet by 2000 the US and the EU refused to sign an agreement, which would have fleshed out the detail of the Kyoto Protocol already agreed to in $1997 .{ }^{4}$

In short, once the temporal dimension of prolonged international negotiations is taken into account it becomes clear that state preferences are fluid not fixed. The preferences of states fluctuate over the course of an extended negotiation. The questions then are how and why?

\section{How and Why Do State Preferences Change? Identifying Internal and External Factors}

This section begins the work towards capturing the temporal dimension of long negotiations, and hence answering these questions, by identifying those factors that appear important to explaining changes in state behavior. First however, a word about the empirical study from which this article draws. To understand what factors lead to changes in state behavior in protracted negotiations, an empirical study was undertaken of the US and the EU during the Kyoto phase of the climate negotiations. Guided by the lines of inquiry discussed above, the focus was on discovering the manner in which domestic, international and transnational factors influence state behavior. To do so, the study relied on 105 elite interviews with representatives from state and non-state actors who were intimately involved in the negotiations (See Author 2011: Ch 1). Although the findings of this empirical study can be generalized to theoretical propositions, based on only two case studies drawn from one set of prolonged negotiations there are limits to how far they can be generalized to populations (Yin 2009: 9). Further research is needed to test these theoretical propositions across a wider range of cases, and across other issue areas. For example, given the protracted nature of the Uruguay Round and the Doha Round, the international trade negotiations would likely provide a rich body of data for future analysis of prolonged international negotiations.

That being said, drawing on an analysis of existing theories of international negotiations and the findings of the empirical study two sets of factors appear important to explaining variations in state behavior: internal factors and external factors. Internal factors refer to variables that precipitate a direct shift in state behavior via the national, international or transnational level. Internal factors include the level of engagement or mobilization of actors, changes in the strategies of actors, or changes in networks of actors, among others. The increased engagement of a treasury department in the domestic discussions is an example of

\footnotetext{
${ }^{4}$ For a review of the climate change negotiations during this period, see among others, (Bodansky 1993, Oberthur \& Ott 1999, Ott 2001).
} 
such an internal factor. External factors, on the other hand, refer to variables that shift multiple internal factors and operate independently of the stage of the negotiations, that is, they operate without regard to the movement between the bargaining and the ratification stage. External factors include exogenous shocks, changes in the state of expert knowledge and challenges from other international regimes. For example, a global financial crisis, a nuclear meltdown or a catastrophic hurricane are all possible external shocks that may change state behavior. In general, the causal chain between an internal factor and a change in state behavior is shorter and easier to identify than the causal chain between an external factor and a change in state behavior. Put differently, internal factors are more proximate than external factors, and as a result it is easier to draw inferences from internal factors than it is external ones. $^{5}$

Before discussing each set of factors, several caveats need to be made. First, it is not always possible to draw clear lines around individual factors and there is much overlap, especially given the capacity of one internal factor, such as a new actor, to directly influence another factor, such as the power of a coalition. Second, it should be clear that the intention here is to identify variables that are critical to explaining changes in state behavior. Hence, we are not interested in factors that, though they may be important to explaining the differences between the behavior of two or more states, such as the type of domestic political institutions, are not expected to change in the course of prolonged international negotiations. Third, the set of internal and external factors discussed is by no means exhaustive, given it was not possible in the context of the research timeframe to look beyond the empirical study discussed above.

\section{Internal factors}

The first and most important internal factor is the level of engagement or mobilization of actors. In prolonged negotiations when actors mobilize there is the potential for new networks between actors and changes in the distribution of the power and preferences of coalitions. As Schattschneider (1960) first pointed out, which stakeholders are mobilized and which are not matters because it affects the balance of forces between actors. As a result, as actors engage and disengage it will create the conditions for new winning and veto coalitions to emerge at the domestic, international and transnational level. This might mean the intervention of a treasury department into bureaucratic debates (Allison 1971), or a new environmental NGO

\footnotetext{
${ }^{5}$ I am indebted to Lawrence Susskind for suggesting the idea of internal and external factors to think about the variations in prolonged international negotiations. Personal communication November 2010.
} 
into international discussions (Newell 2000), or a business group engaging at the transnational level (Keck \& Sikkink 1998). Each new actor could directly precipitate a shift in state behavior.

Second, actors make strategic choices about where and how to negotiate. If they choose a new strategy this could shift state behavior and the outcome. For example, some authors use the term "forum-shopping" (Braithwaite \& Drahos 2000) or "different pathways" (RisseKappen 1995b) to describe how actors take actions in different forums or at different levels to influence state behavior and the outcome of a negotiation. For example, traditionally less powerful actors, such as environmental NGOs, may decide to shift their activities to the international level because of limited access to government at the domestic level, whereas strong actors may not need to do so because of their powerful position at home. Or, business groups may supplement their domestic lobbying by engaging in transnational actions as well.

Third, if we consider the state as a networked entity where the state acts as an agent for the interests of non-state actors and other actors act as agents for states, variations in these networks could influence state behavior. For example, the importance of "policy networks" is well established in the governance literature where "formal institutional and informal linkages between governmental and other actors" shape state behavior (Rhodes 2006: 246). They do so by limiting participation in the policy process; deciding which issues will be included and excluded from the policy agenda; shaping the behavior of actors through the rules of the game; and, among other things, privileging certain interests over others (Rhodes 2007: 1251). Of course, it is not only national level networks but transnational ones as well that are important (Keohane \& Nye 1974, Risse-Kappen 1995b, Slaughter 2004). When these networks change, as they naturally do in the course of prolonged negotiations, so too will state behavior.

Fourth, the mobilization of actors and changes in networks mean the possibility of new coalitions. The two-level framework shows how important the distribution of domestic coalitions is to understanding a state's position and its' willingness to sign an agreement (Putnam 1988). In fact, much of the behavior of the US and the EU in the Kyoto phase of the climate negotiations can be accounted for by the variations in influence of progressive and regressive coalitions (Author 2011). Changes in the distribution of the power and preferences 
of these coalitions then, have the potential to directly shift state behavior. ${ }^{6}$ However, in international negotiations it is not just the possibility of new coalitions at the domestic level, but at the international and transnational level as well, that may shape outcomes. As international negotiations drag on, new winning or veto coalitions can emerge to re-shape the dynamics of the negotiations and with it the outcome.

While the internal factors identified so far are critical, a key question in the case of prolonged international negotiations is; why do these factors change? In other words, why do new actors mobilize? Why do actors change their strategies? Why do networks among actors change? And, what is it that shifts the distribution of coalitions over time? The short answer is that these changes are the function of the following internal factors: domestic political incentives, the stage of the negotiations and the preferences of the COGs.

Domestic political incentives and the stage of the negotiations are interrelated. As negotiations progress the domestic political incentives for government agencies, non-state actors, or COGs will change and with it their level of engagement. The political incentives for these actors will in turn be a function of how they perceive the tangible costs and benefits of the agreement under negotiation which, as others have pointed out, is directly related to the stage of the negotiations. For example, in elaborating on the two-level game, Moravscik (1993) and Evans (1993) note that as negotiations move from the bargaining to the ratification stage the costs and benefits of an agreement become clearer, and as a result, domestic groups will mobilize in defense of their interests. This in turn will bring new actors into the game. In other words, as some actors push for an agreement it engages other actors to push against (Spector \& Zartman 2003, Spector 2003). ${ }^{7}$

The evidence from the US and the EU in the climate negotiations shows that in both cases state and non-actors mobilized as their political incentives changed in response to the changes in the stage of the negotiations. In the US, as negotiations over ratification of the Kyoto Protocol wore on in the late 1990s, the engagement of economic agencies and business groups increased as the US emission reduction targets were defined and the economic costs of meeting such targets became tangible. In contrast, in the early 1990s a progressive

\footnotetext{
${ }^{6}$ This is largely consistent with liberal theory, which stresses that the nature of domestic political representation helps to determine whose social preferences dominate state policy. As a result, policy tends to be biased in favour of the governing coalitions or powerful domestic groups favoured by representative institutions, be they armies, bureaucracies or societal groups (Moravcsik 2008).

${ }^{7} \mathrm{I}$ am grateful to William Zartman for bringing my attention to this point. Personal communication January 2011.
} 
coalition of environmental interests was able to push their agenda relatively unopposed because negotiations concerned a tentative agreement where the costs and benefits were unclear. It was similar in the EU, where state actors, such as the Directorate-General for Industry in the European Commission, acknowledged that it was not until after Kyoto, that is the ratification stage, that they started paying attention (Author 2011).

Finally, COGs are crucial to explaining the type of agreement that states are willing to sign (Putnam 1988, Evans 1993, Moravcsik 1993). However, in protracted negotiations there is the potential for changes in the preferences of COGs if there is a change in government, or a change in the beliefs or political incentives of an existing COG. While a change in government is possible in shorter negotiations, it is almost inevitable in protracted negotiations and can lead to a fundamental change in the preferences of the COG. For instance, the electoral success of the Green Party in Europe in the late 1990s and the resulting shift in the composition of the Environment Council directly influenced the preferences of the Council, which acted as the COG for the EU (Author 2011: Ch 5). Yet even when there is no change in government, there is the potential for the preferences of a COG to change with a change in their beliefs or political incentives. For example, when voters are not attentive, it can be expected that politicians will weigh more heavily the voices of organized interest groups on either side of the issue (Harrison \& Sundstrom 2007). As voter interest changes so will the domestic political incentives of the COG. In the same fashion, the capacity of COGs to manipulate these domestic constraints will also vary over time. Evans (1993) concludes that as international negotiations move from the bargaining to the ratification stage the relative autonomy of the COG to manipulate these pressures decreases. This is because as discussions focus on ratification and tangible costs and benefits, more actors mobilize to advance or defend their interests and hence the constraints on the COG increase. Using the two-level perspective, Trumbore (1998) makes a similar observation that the higher the intensity of the issue under negotiations the greater the likelihood that public preferences will constrain decision-makers. Such variations are likely to become more acute the longer the negotiations. For example, in the US, the preference of the White House, particularly VicePresident Al Gore, was for an ambitious climate agreement based on his own personal beliefs, which in the early 1990s were in line with his domestic political incentives. However, by the time of the negotiations in 2000, domestic actors had mobilized in opposition to an international agreement, and his capacity to manipulate these pressures were limited by a new set of domestic political incentives as a result of his bid for the presidency (Author 2011). 


\section{External factors}

Whereas internal factors precipitate a direct shift in state behavior, external factors, as noted, indirectly shift state behavior by re-shaping the context in which the negotiations take place. External factors are independent of the stage of the negotiations, that is, they operate without regard to the movement between the bargaining and the ratification stage. However, the longer causal chain between an external factor and a change in state behavior means that it is not always possible to specify its precise affect.

First, exogenous shocks, or events, have the potential to transform the context in which international negotiations take place (Zartman 2003). The most common pathway is where a dramatic event, or series of events captures the imagination of mass publics, after media organizations dramatize the event, and state actors are forced to act to placate the public and the media (Braithwaite \& Drahos 2000, Downs 1972). The Bhopal accident in 1984 and Chernobyl accident in 1986 are classic cases of exogenous events that catalyzed mass publics and forced states to act both domestically and internationally. Such events, which are more likely the longer the negotiation, can shift multiple internal factors as new actors mobilize in response to new political incentives, which in turn affect the distribution of coalitions and so on. In short, an exogenous shock will indirectly shift state behavior.

A second external factor is the state of expert knowledge among policy elites. Epistemic communities, which have an authoritative claim to policy-relevant knowledge within a specific domain or issue-area, can promote organizational learning by helping to create shared understandings in their specialized field (Haas 1992). In prolonged international negotiations, knowledge within an epistemic community can filter through to change the state of expert knowledge among policy elites. The evolution in the state of knowledge is an external factor because it develops independently of political incentives and the stage of negotiations, yet it has the potential to shift multiple internal factors simultaneously and, consequently, state behavior. One pathway by which this can occur is by affecting the personal beliefs of statesmen and in turn, their preferences which, as we have seen, are critical to explaining changes in state behavior (Goldstein \& Keohane 1993). Another is by permeating public opinion so as to shift domestic political incentives. ${ }^{8}$ There is much evidence to indicate that the UN Intergovernmental Panel on Climate Change (IPCC), an

\footnotetext{
${ }^{8}$ I am grateful to Robert Putnam for highlighting the importance of knowledge as a factor external to the twolevel game. Personal communication November 2010.
} 
epistemic network of climate scientists, directly affected the behavior of the US and the EU in precisely this way during the international climate negotiations (Author 2011).

Finally, other international regimes can act as an external factor. Zartman (2003: 29-31) has pointed out that competing efforts to deal with aspects of the same problem in overlapping geographic or functional areas occur at the intersection of various regimes. As a result, exogenous challenges can come from other regimes. For example, there is evidence to suggest that the international ozone regime has for a long time had an impact on the climate regime (Author 2011). More recently, a collection of studies has highlighted the "strategic linkages" between the climate regime and other regimes, such as those to combat desertification and protect biological diversity, among others (Jinnah 2011).

\section{Toward an "Ideal Type" Framework: An Immature and Mature Game}

Having identified a set of internal and external factors that have the potential to shift state behavior, we are now in a better position to develop an "ideal type" framework for analysing prolonged international negotiations. As we have seen, state behavior does not shift in response to one particular factor. Rather, the type of agreement a state is willing to sign will change based on the complex interaction of multiple internal and external factors. But this begs the questions: how and when?

To provide a clearer picture, this section suggests that state behavior can be located along a continuum, of which the opposite ends are an immature game and mature game. Of course, state behavior will rarely, if ever, conform with either of these extreme positions. Yet it is hard to think more critically about the temporal dimension of prolonged international negotiations without making these types of abstractions. Indeed, they might equally be thought of as "ideal types", that is, a construct derived from observable reality although not conforming to all of the characteristics because of deliberate simplification (Burger 1976). In other words, the very concept of an ideal type acknowledges that the real world will only approximate, rather than fully mirror an ideal type of state behavior.

Before elaborating on what immature and mature games involve, it is important to clarify several points. First, the "ideal types" are used to characterize the position of a state in the negotiations, not to characterize the international negotiations as a whole. In other words, it is not the international climate change negotiations that are mature or immature but the position of a party to the negotiations. For example, the position of the US or the EU might resemble 
certain elements of an immature or mature game, but not the negotiations as a whole. Because each ideal type is linked to the stage of the negotiations it is likely that the movement of a state along the continuum will parallel that of other states. That being said, states will move at different speeds based on their domestic, international and transnational interactions, and it is entirely possible than some states will remain in an immature game while others have matured. Second, in reality the types of state behavior are non-binary because in the real world there is unlikely to be a complete distinction between the characterizations of state behavior as an immature game or a mature game. Third, a state's movement along the spectrum between both positions is non-linear. State behavior does not necessarily move in one direction from an immature game to a mature game or vice versa. Instead, state behavior can oscillate between ideal types over time.

\section{An immature game}

A state will be involved in an immature game when:

(i) The international negotiations are in the "bargaining phase";

(ii) The costs and benefits of the tentative agreement are intangible;

(iii) Interested actors are minimally mobilized;

(iv) The COG has considerable capacity to manipulate domestic constraints; and

(v) No external factors are in play.

An immature game refers to a position in which many or most of the interested state and nonstate actors, with which a state interacts via the domestic, international and transnational level are not mobilized. This is because there are limited political incentives to get involved in the bargaining phase, given negotiations are about a tentative agreement where the costs and benefits of a particular outcome are not yet tangible. As a result, COGs will have a greater capacity to manipulate domestic constraints according to their preferences. Take the example of government actors in the inter-agency discussions. In an immature game very few of these actors are engaged. The senior ranks of government agencies have limited knowledge or interest in the issue because at this stage they will not be directly affected by the negotiated outcome, and competing policy priorities mean that their attention and resources are devoted 
elsewhere. The same is true of non-state actors such as environmental NGOs and business groups.

This game will be further characterized by the absence of external factors. In an immature game, no exogenous shocks will have taken place to catalyse the public and the media. The state of expert knowledge among policy elites will be immature. Epistemic communities will have only begun to form, or where they have formed, they will not have established a consensus among policy elites about the problem that was different to the state of knowledge before the negotiations began. Other international regimes that are engaged in competing efforts to deal with aspects of the same problem will not have provided any exogenous challenges to actors engaged in the protracted international negotiations.

Finally, the elements of an immature game will impact the likelihood of an agreement and the type of agreement that is reached. States negotiating in immature games will have a smaller set of possible international agreements that are acceptable domestically, or in the words of Putnam's two-level game, smaller win-sets. To be sure, because very few interested actors are mobilized a state will have homogenous interests. While Putnam argues that this will make agreement less likely because the smaller the win-set the less likely it is to overlap with another party's win-set, this will not always hold (Putnam 1988: 437-438). Putnam claims that a state that is firmly committed to a single policy will be less able to strike a deal internationally than one that is internally divided (Putnam 1988: 444-445). For example, if the policy of Country A is to support energy companies because they are the only groups mobilized, and the policy of Country B is to support emission reductions because environmental NGOs are the only groups mobilized it is unlikely that country A and B will be able to reach an agreement. If however, country $B$ is internally divided because environmental interests and energy companies are mobilized it is possible that the win-sets of both parties will overlap via the preferences of energy companies making agreement more likely. However, the likelihood of an agreement is not simply a function of the probability that win-sets will overlap. Agreement is also contingent on the content of the agreement. In other words, Country A and Country B may both have small win-sets, but if environmental NGOs are the only groups mobilized in both countries their win-sets will still overlap. Furthermore, because in an immature game international negotiations are in a bargaining phase and therefore focused on a tentative agreement, if an agreement is reached, a nonbinding agreement that emphasizes procedures and principles will be the norm. 


\section{A mature game}

A state will be involved in a mature game when:

(i) The international negotiations are in the "ratification phase";

(ii) The costs and benefits of the agreement are tangible;

(iii) Interested actors are completely mobilized;

(iv) The COG has limited capacity to manipulate domestic constraints; and

(v) All external factors are in play.

In direct contrast, a mature game refers to a position in which many or most of the interested actors with which a state interacts via the domestic, international and transnational level are mobilized. This is because there are political incentives to get involved given that the international negotiations have entered the ratification phase, and the costs and benefits of a particular outcome are now tangible. As a result, COGs will have less capacity to manipulate domestic constraints according to their preferences. Again, using the example of government actors in the inter-agency discussions, in a mature game most actors are engaged. The senior ranks of agencies ensure that their agency is aware of the issues being negotiated and devote sufficient attention and resources to formulate and advocate specific negotiating positions because they will be directly affected by the negotiated outcome. The same is true of nonstate actors such as environmental NGOs and business groups.

Further, in a mature game, external factors will be felt with full effect. An external event, such as an environmental crisis, or an economic shock, will have occurred to catalyze the public and the media. The state of expert knowledge among policy elites will have matured so there is a consensus about the problem and the need to resolve it. This consensus will have been established by well-developed epistemic communities, which have had close interaction with policy elites and have likely influenced COG preferences as well. Further, other international regimes will be engaged in competing efforts to address the same problem, which will have a direct effect on the actors engaged in the international negotiations.

Finally, as with an immature game, the elements of a mature game will impact the likelihood of an agreement and the type of agreement that is reached. States negotiating in mature games 
are likely to have larger win-sets because most state and non-state actors are mobilized. Admittedly, this will not always be the case. When new actors mobilize in a mature game this could also take options off the table. For example, if energy companies mobilize to form a veto coalition they could reduce the size of the win-set. That being said, when win-sets are larger, again, according to Putnam, agreement will be more likely because the larger the winset the more likely it is to overlap with another party's win-set (Putnam 1988: 437-438). However, the likelihood of agreement is also contingent on the content of the agreement, so larger win-sets do not always increase the prospect of agreement. To this set of complex relationships one more needs to be added. The paradox of a larger win-set is that negotiators will be less powerful than those with a small win-set. If a negotiator has a large win-set he can be "pushed around" by other negotiators, yet if his win-set is small he will be at a bargaining advantage because he can respond that: "I'd like to accept your proposal, but I could never get it accepted at home" (Putnam 1988: 440). ${ }^{9}$ Furthermore, because international negotiations are in a ratification phase where negotiations are about a legal instrument, if an agreement is reached, a legally binding agreement that includes some implementation requirements will be the norm.

\section{Strategies to Influence State Behavior in Prolonged International Negotiations}

The concept of an immature and mature game highlights the complex processes that shape prolonged international negotiation outcomes. In such a world, there are strategic opportunities for highly networked actors to influence state behavior by making strategic choices at the domestic, international or transnational level to mobilize other actors, establish coalitions, manipulate COG preferences, and in turn, shape international negotiation outcomes. In other words, to engage in what we might refer to as "constructive management". This recognizes that because preferences are fluid in a long negotiation actors have considerable agency to influence state behavior. This is especially so in an immature game given the game itself is fluid, networks are open and coalitions are not highly structured. Even in a mature game, which is more structured and likely to be dominated by powerful actors, weak actors are not without agency. The fact that preferences are fluid in a long negotiation means that actors will always have a degree of agency no matter how weak they are. Some actors may bleakly view a mature game as a triumph of power, and in many

\footnotetext{
${ }^{9}$ This paradox was first pointed out by Schelling (1960: 19).
} 
cases it will be, but in a long negotiation actors will always have opportunities to shift the preferences of states.

In this section we identify strategies that traditionally weak actors can employ to steer international negotiations by constructively influencing the negotiating positions of states and the type of agreements they are willing to sign. These strategies could, of course, be employed in shorter one-off negotiations, but they are likely to be uniquely effective when they are used to exploit the strategic opportunities that arise in long negotiations. Accordingly, the choice of strategy will depend not only on the goals of the actor, but importantly in the context of prolonged international negotiations, it will depend on which elements of an immature or mature game are present in the negotiations. In other words, some strategies will be most effective when key elements of an immature game are present and others when a state's position more closely represents a mature game. Each strategy represents an attempt at constructive management.

\section{Four strategies for exploiting the elements of an immature game}

\section{(i) Exploiting the minimal mobilization of interested actors}

In an immature game there is a unique strategic opportunity for traditionally weak actors to dominate discussions because more powerful actors are not mobilized. As discussed above, which actors are mobilized and which are not matters because it affects the balance of forces between actors. This is particularly pertinent in international environmental negotiations where key actors - environment agencies and environmental NGOs - are often the weakest actors. For example, in the US and the EU during the climate negotiations, the dominance of a progressive coalition of environmental interests in the early 1990s can be largely attributed to limited mobilization of other powerful actors such as treasury departments or fossil fuel companies (Author 2011).

Accordingly, when interested actors are not mobilized weak actors should actively engage in the discussions as early as possible to exploit the circumstances. In other words, weak actors should go in hard and early to influence state behavior. For state actors this means that the senior ranks of an agency should engage with the issues being negotiated and devote sufficient attention and resources to formulate and advocate specific negotiating positions, which are likely to have more influence because of the absence of alternatives presented by 
other actors. The same will be true for non-state actors whose positions both on questions of policy and politics will be largely uncontested.

Weak actors who exploit these circumstances will therefore have a unique opportunity to frame the discussions. One of the most effective ways that actors can affect state behavior is by strategically framing debates to draw attention to their concerns. As other researchers have shown, the actor or coalition of actors that succeeds in establishing a frame that is consistent with its goals is likely to reap the greatest gains from negotiations (Braithwaite \& Drahos 2000, Joachim 2003, Odell \& Sell 2006). For example, Sell (2003: 182) has argued that "ideas that are seen as legitimate, appropriate, or correct have a better chance of prevailing" in policy contests. Consequently, a fruitful approach for weak actors might be to exploit the characteristics of an immature game and inform other actors before they have formed a preference on the issues being negotiated. In other words, to frame the policy debate before other actors have an opportunity to do so. The dominant frame is likely to be particularly influential at this point given the limited knowledge other have actors about the issues under negotiation.

\section{(ii) Infiltrating and manipulating networks and coalitions}

In a networked world, as discussed, where the state acts as an agent for the interests of nonstate actors and other actors act as agents for states, highly networked actors have the capacity to shape state behavior (Rhodes 2006: 426, Rhodes 2007). For traditionally weak actors this is often difficult given that policy networks, for example, are often inaccessible. However, in an immature game where a tentative agreement is being negotiated, the costs and benefits of which are not yet tangible and, as a result, interested actors are minimally

mobilized, domestic networks and coalitions are likely to be fluid. This will provide a strategic opportunity for weak actors to move in and out of this space with greater ease. As a result, a second and related strategy for weak actors is to infiltrate and manipulate domestic networks and coalitions when they are most fluid.

The success of such a strategy was evident in the US prior to the negotiations in Kyoto in 1997. Environmental NGOs were able to infiltrate and then manipulate orthodox policy networks. In the US, staff from the Environmental Defense Fund (EDF), who had developed personal relationships with White House advisors, managed to get 'in the room' with key White House officials when decisions were made about the US position on emissions trading 
(Author 2011). According to interviews with former US officials, EDF, which had played an integral role in developing emissions trading as part of the Clean Air Act Amendments in 1992, was critical in persuading the Clinton administration to take a similar approach on climate change because it was able to maneuver inside key policy networks (Author 2011).

Further, when the structure of the domestic discussions is fluid, state actors also have the capacity to manipulate or steer discussions before more powerful actors mobilize. Prior to 1996 in the US, the Council of Environmental Quality (CEQ), led by Katie McGinty (Vice President Al Gore's confidante), chaired the inter-agency discussions that developed the US negotiating position for COP 1in Berlin in 1995. However, by 1996, as other interested actors mobilized and the game matured, the National Economic Council (NEC) successfully lobbied the White House to co-chair the internal discussions with the CEQ. This changed the interagency discussions 'considerably' because the Environmental Protection Agency (EPA) and the State Department had to contend with the growing input from the Department of Treasury, who were often opposed to their positions (Author 2011). In other words, the opportunity to manipulate these networks was restricted once the key elements of an immature game were no longer present.

\section{(iii) Targeting the COGs capacity to manipulate domestic constraints}

While the preferences of the COG are crucial to explaining state behavior, their capacity to manipulate domestic constraints is greatest when the international negotiations are in the bargaining phase. The lesson for actors, especially weak actors who have fewer alternative pathways to influence state behavior, is to target the COG in the bargaining phase. If an actor is successful in influencing a COG's preference at this point in the negotiations it is more likely that these preferences will be reflected in a state's negotiating position given the greater relative autonomy of the COG.

A COG's preferences will be informed both by personal beliefs and the desire to enhance their domestic political position. Accordingly, actors should target both these avenues to persuade the COG to adopt a position consistent with their interests. First, state and non-state actors should engage directly with the COG and their senior advisors to affect their personal beliefs by persuading them of the importance of the issues being negotiated. Of course, this will be easier in an immature game, when such networks will be more porous. One way to do 
this is to facilitate the flow of expert knowledge about the problem to the COG, as we will discuss in more detail below.

Second, actors should attempt to manipulate the political incentives of the COG in favor of their desired outcome. In international negotiations a good option for weak actors who are unable to mobilize economic resources is to target the reputation of the COG. The evidence, especially from the US case study, suggests several ways that this can be done effectively. One way is to target new governments that appear more susceptible to the costs of reputation because they are trying to stand apart from the previous government. This was certainly the case in the US with the Clinton administration's desire to 'distinguish itself' from the previous Bush administration (Author 2011). Second, COGs are more susceptible to reputational pressures if they have been recently admonished on the international stage, especially over a similar issue such as the provision of a global public good (Downs \& Jones 2002). In the US this was manifest in the months before Kyoto after the US had been ridiculed by the international community for announcing it would not sign an international treaty to ban land mines (Author 2011).

\section{(iv) Facilitating the flow of expert knowledge to policy elites}

The basic premise of constructive management is that state preferences matter to international outcomes, that they are fluid and that these preferences can be socially constructed. In an immature game where COGs and policy elites have not developed firm preferences on the issue under negotiation, weak actors can facilitate the flow of expert knowledge to these actors to inform their beliefs and, in turn, their preferences and negotiating position. Again, this will work best in an immature game because networks are more fluid and COGs have a greater capacity to manipulate domestic constraints based on their beliefs.

Epistemic communities can play a key role in this process. As noted, epistemic communities can help to create shared understandings among policy elites about the nature of a problem (Haas 1992). Weak actors can facilitate the flows of such information. State actors should develop networks with key policy elites and arrange for inter-agency discussions to include experts from epistemic communities to help drive consensus. Non-state actors should play a complementary role organizing to brief policy elites in government, and where possible the $\mathrm{COG}$, of the latest developments in the epistemic community's knowledge. 


\section{Four strategies for exploiting the elements of a mature game}

The key elements of a mature game make it much more difficult for weak actors to influence state behavior. With international negotiations in the ratification phase, powerful actors are engaged as the tangible costs and benefits of a negotiated agreement are thrashed out. The result for weak actors is that their positions will be increasingly contested and domestic networks and coalitions are likely to be much more structured and closed off to the infiltration and manipulation that may have been possible earlier in the negotiations. Nevertheless, because preferences are fluid actors will always have a degree of agency to marshal state behavior. Accordingly, there are strategies which actors can employ to affect a state's negotiating position and the type of agreement it is willing to sign.

\section{(i) Meeting the demand of policy elites for expert knowledge}

First, and very briefly, weak actors should persist in facilitating the flow of expert knowledge to policy elites. While this will be more difficult in a mature game, it still has the potential to shift the preferences of the COG and policy elites. One element of a mature game that will advance this strategy is that demand for information from policy elites is likely to be greater in the ratification stage when discussions have turned to distributing tangible costs and benefits among domestic interest groups. As Haas (1992) argued, the language of science will penetrate politics especially in issue areas with high complexity and uncertainty where there is demand for such knowledge from policymakers.

\section{(ii) Exploiting exogenous shocks}

Exogenous shocks have a very real potential to shift state behavior by catalyzing mass publics and forcing states to act both domestically and internationally. In such an atmosphere actors who have a pre-prepared model to address the crisis will have an enormous appeal to state actors looking for a solution. For example, if a nuclear meltdown forces a state to act, actors with a pre-prepared model to re-regulate energy production and phase out nuclear power will be in a powerful position. Indeed, the key for weak actors is that their influence depends on the power of the model, not on the power of the advocate. As Braithwaite and Drahos (2000: 589) point out, the politics of modeling is not about problems looking for solutions, but solutions waiting for the right problem and moment to justify their implementation. Accordingly, in a mature game where weak actors have been outmaneuvered by more powerful actors and are closed off from policy networks, an exogenous shock can 
provide a strategic opportunity, if they have a model in hand, to influence state behavior and steer the negotiations toward an outcome consistent with their interests.

\section{(iii) Leveraging other international regimes}

Further, in the context of a mature game dominated by powerful interests, weak actors, where possible, should engage with other international regimes to influence state behavior. As we have seen, one international regime, such as the ozone regime, can provide an exogenous challenge to a second regime, such as the climate regime if they are involved in competing efforts to deal with aspects of the same problem (Zartman 2003). Where this occurs, strategic opportunities may exist for weak actors whose influence has been muted in one international regime to shift their attention to a second regime and use it as leverage. If possible, actors should engage a stronger regime as this is likely to have a greater capacity to provide an exogenous challenge. For instance, environmental NGOs participating in the climate negotiations may seek to affect the rules and boundaries of the international trade regime with the hope of spurring changes in the climate regime. One avenue could be to introduce rules on border tax adjustments, that is, fees levied by carbon-taxing countries on goods manufactured in non-carbon-taxing countries (New Economics Foundation 2003, Stiglitz 2006, Stokke 2004).

\section{(iv) Building transnational coalitions}

Finally, as the transnational perspective points out "transnational relations matter in world politics", and state behavior in international relations cannot be understood without taking account of the cross-boundary activities of sub-units of government and non-state actors (Risse-Kappen 1995b: 280). In a mature game that is structured by powerful interests who tend to dominate domestic networks and coalitions, a good option for weak actors is to develop transnational networks. The evidence from the climate negotiations indicates that transnational networks are most effective at influencing domestic and international policy outcomes when they include state and non-state actors. For example, by the mid-to-late 1990s a transnational network comprised of economists within the European Commission and officials in the EPA had developed in the pursuit of emissions trading. They had also teamed up with non-state actors, such as the US NGO the Center for Clean Air Policy, to advocate

emissions trading in Europe (Author 2011; Skjaerseth \& Wettestad 2008). Further, in a mature game there is the opportunity for weak actors in one country to enroll more powerful 
actors in another. For instance, European business groups could have networked with economic officials in the US to ensure that they vetoed any international agreement that would prove costly to American business as well as to European business groups.

\section{Conclusion}

In order to understand many of the most significant international negotiations that take years and sometimes decades to conclude, such as the climate change negotiations, theories need to take account of the temporal dimension. The temporal dimension matters because it draws our attention to variables, strategies and outcomes that are not apparent if the focus is on individual negotiation outcomes.

However, the fluidity of preferences that characterizes prolonged international negotiations makes it impractical to develop the type of parsimonious theory toward which theorists often strive. ${ }^{10}$ If preferences were fixed, like neutrons, it would be possible to develop if-then propositions, but in a long negotiation preferences are positively charged one year and negatively charged the next. Accordingly, in circumstances of fluidity, attempts at parsimonious theory may provide elegance, but they will also limit insights, and fail to enrich our understanding of the ebb and flow of prolonged international negotiations. ${ }^{11}$

This article's intended contribution is to both the theory and practice of international negotiations. First, by considering the temporal dimension it is clear that the preferences of actors, including states, are fluid not fixed; that their preferences fluctuate over the course of an extended negotiation. Accordingly, this article first identifies a set of internal and external factors distinctive to prolonged international negotiations that explain how and why the negotiating positions and the type of agreement states are prepared to sign can change. It suggests that state preferences are influenced by a variety of variables such as, the different levels of engagement of actors, the preferences of chiefs of government and the changing state of expert knowledge among policy elites. Second, because preferences are fluid, actors, including traditionally weak actors, have considerable agency to influence state behaviour. As a result, there are strategic opportunities in the course of a protracted negotiation for actors to steer negotiations toward their preferred outcomes. Third, the type of agreement possible and the likelihood that an agreement will be reached will also be contingent on the

\footnotetext{
${ }^{10}$ See for example, (Moravcsik 1997).

${ }^{11} \mathrm{I}$ am indebted to Peter Drahos for drawing my attention to this point and its implications for theory.
} 
stage of the negotiations. Indeed, this article has developed an ideal type framework as a first step for understanding the temporal dimension of prolonged international negotiations and prescribing specific strategies that state and non-state actors can use to shape international outcomes. Of course, these conclusions need to be tested across a wider range of cases, and across other issue areas.

Notwithstanding, this article invites negotiation researchers and practitioners representing state and non-state actors to take account of the temporal dimension of prolonged international negotiations. For researchers, this requires recognizing that the fluidity of preferences and that theoretical frameworks that capture the variations in state behavior will not always achieve parsimony. For practitioners, especially those representing traditionally weak actors, it invites a consideration of the strategic opportunities that they have in long negotiations to influence state behavior by pursuing specific strategies at the domestic, international and or, transnational level. 


\section{References}

Allison, Graham (1971). Essence of Decision: Explaining the Cuban Missile Crisis. New York: Harper Collins.

Benedick, Richard (1991). Ozone Diplomacy: New Directions in Safeguarding the Planet. Cambridge: Harvard University Press.

Bodansky, Daniel (1993). "The United Nations Framework Convention on Climate Change: A Commentary". Yale Journal of International Law, 18, 451-558.

Braithwaite, John and Drahos, Peter (2000). Global Business Regulation. Cambridge: Cambridge University Press.

Breitmeier, Helmut, Young, Oran and Zurn, Michael (eds.) 2006. Analyzing International Environmental Regimes: From Case Study to Database, Cambridge: The MIT Press.

Burger, Thomas (1976). Max Weber's Theory of Concept Formation: History, Laws and Ideal Types. Durham: Duke University Press.

Chasek, Pamela (1997). "A Comparative Analysis of Multilateral Environmental Negotiations". Group Decision and Negotiation, 6, 437-461.

Chasek, Pamela (2001). Earth negotiations: analyzing thirty years of environmental diplomacy. Tokyo: United Nations University Press.

Crump, Larry and Zartman, William I (2003). "Multilateral Negotiation and the Management of Complexity". International Negotiation, 8, 1-5.

Daugberg, Carsten and Swinbank, Alan (2009). Ideas, Institutions, and Trade: The WTO \& the curious role of EU farm policy in trade liberalization. Oxford: Oxford University Press.

Downs, Anthony (1972). "Up and down with ecology - the "issue-attention cycle"'". Public Interest, 28, Summer: 38-50.

Downs, G and Jones, M (2002). "Reputation, Compliance, and International Law". Journal of Legal Studies, 31, 1: S95-S114.

Druckman, Daniel (2001). "Turning points in international negotiations: A comparative analysis". Journal of Conflict Resolution, 45, 519-544.

Enia, Jason (2009). "Sequencing Negotiating Partners: Implications for the Two-Level Game?". Negotiation Journal, 25, 3: 357-383.

Evans, Peter (1993). Building an Integrative Approach to International and Domestic Politics: Reflections and Projections. In: Evans, Peter, Jacobson, Harold \& Putnam, Robert editor, Double-Edged Diplomacy: International Bargaining and Domestic Politics Berkeley: University of California Press.

Goldstein, Judith and Keohane, Robert (1993). Ideas and Foreign Policy: An Analytical Framework. In: Goldstein, Judith \& Keohane, Robert editor, Ideas and Foreign Policy: Beliefs, Institutions and Political Change. Ithaca: Cornell University Press.

Haas, Peter (1989). "Do Regimes Matter? Epistemic communities and Mediterranean pollution control". International Organization, 43, 3: 377-403.

Haas, Peter (1992). "Introduction: Epistemic Communities and International Policy Coordination". International Organization, 46, 1: 1-35.

Hafner-Burton, Emilie, Kahler, Miles and Montgomery, Alexander (2009). "Network Analysis for International Relations". International Organization, 63, 559-592.

Harrison, Kathryn and Sundstrom, Lisa (2007). "The Comparative Politics of Climate Change". Global Environmental Politics, 7, 4: 1-18.

Hasenclever, Andreas, Mayer, Peter and Rittberger, Volker (2000). "Integrating theories of international regimes". Review of International Studies, 26, 3-33.

Jinnah, Sikina. 2011. "Climate Change Bandwagoning: The Impacts of Strategic Linkages on Regime Design, Maintenance, and Death". Global Environmental Politics 11, 3: 1-9. 
Joachim, Jutta (2003). "Framing Issues and Seizing Opportunities: The UN, NGOs, and Women's Rights". International Studies Quarterly, 47, 247-274.

Jonsson, Christopher and Tallberg, Jonas (1998). "Compliance and Post-Agreement Bargaining". European Journal of International Relations, 4, 4: 371-408.

Keck, Margaret and Sikkink, Kathryn (1998). Activists Beyond Borders: Advocacy Networks in International Politics. Ithaca: Cornell University Press.

Keohane, Robert and Nye, Joseph (eds.) 1972. Transnational Relations and World Politics Cambridge: Harvard University Press.

Keohane, Robert and Nye, Joseph (1974). "Transgovernmental Relations and International Organizations". World Politics, 27, 1: 39-62.

Krasner, Stephen (1983). Structural causes and regime consequences: regimes as intervening variables. In: Krasner, Stephen (ed.) International Regimes. Ithaca: Cornell University Press.

Lake, David (2008). The State and International Relations. In: Reus-Smit, Christian \& Snidal, Duncan editor, Oxford Handbook of International Relations. Oxford: Oxford University Press.

Lake, David 2010. Rightful Rules: Authority, Order, and the Foundations of Global Governance. ISA Presidential Address.

Levy, Marc, Young, Oran and Zurn, Michael (1995). "The Study of International Regimes". European Journal of International Affairs, 1, 3: 267-330.

Milner, Helen and Moravcsik, Andrew (eds.) 2009. Power, Interdependence, and Nonstate Actors in World Politics, Princeton: Princeton University Press.

Moravcsik, \Andrew (1993). Introduction: Integrating International and Domestic Theories of International Bargaining. In: Evans, Peter, Jacobson, Harold \& Putnam, Robert editor, Double-Edged Diplomacy: International Bargaining and Domestic Politics Berkeley: University of California Press.

Moravcsik, Andrew (1997). "Taking Preferences Seriously: A Liberal Theory of International Relations". International Organization, 51, 4: 513-553.

Moravcsik, Andrew (2008). The New Liberalism In: Reus-Smit, Christian \& Snidal, Duncan editor, The Oxford Handbook of International Relations. Oxford: Oxford University Press.

New Economics Foundation 2003. Free riding on the climate: the possibility of legal, economic and trade restrictive measures to tackle inaction on global warming. London: New Economics Foundation.

Newell, Peter (2000). Climate for Change: Non-state actors and the global politics of the greenhouse. Cambridge: Cambridge University Press.

Oberthur, Sebastian and Ott, Hermann (1999). The Kyoto Protocol: international climate policy for the 21st century. Berlin: Springer.

Odell, John and Sell, Susan (2006). Reframing the issue: the WTO coalition on intellectual property and public health, 2001. In: Odell, John (ed.) Negotiating Trade: Developing Countries in the WTO and NAFTA. Cambridge: Cambridge University Press.

Ott, Hermann E. (2001). "Climate change: an important foreign policy issue". International Affairs, 77, 2: 277-296.

Putnam, Robert (1988). "Diplomacy and Domestic Politics: The Logic of Two-Level Games". International Organization, 42, 3: 427-460.

Raustiala, K. and Bridgeman, N. (2007). "Nonstate Actors in the Global Climate Regime ". Public Law and Legal Theory Paper Research Series, Research Paper No. 07-29.

Rhodes, Rod (2006). Policy Network Analysis. In: Moran, Michael, Rein, Martin \& Goodin, Robert editor, The Oxford Handbook of Public Policy. Oxford: Oxford University Press. 
Rhodes, Rod (2007). "Understanding Governance: Ten Years On". Organization Studies, 28, $1243-1264$.

Risse-Kappen, Thomas (1995a). Bringing transnational relations back in: introduction. In: Risse-Kappen, Thomas (ed.) Bringing transnational relations back in: Non-state actors, domestic structures and international institutions. Cambridge: Cambridge University Press.

Risse-Kappen, Thomas (1995b). Structures of governance and transnational relations: what have we learned? In: Risse-Kappen, Thomas (ed.) Bringing transnational relations back in: Non-state actors, domestic structures and international institutions. Cambridge: Cambridge University Press.

Rosenau, J (2000). Change, complexity, and governance in a globalizing space. In: Pieere, J (ed.) Deabting Governance: Authority, Steering and Democracy. Oxford: Oxford University Press.

Rosenau, J (2007). "Governing the ungovernable: The challenge of a global disaggregation of authority ". Regulation and Governance, 1, 1: 88-97.

Ruggie, John, Katzenstein, Peter, Keohane, Robert and Schmitter, Philippe (2005). "Transformations in World Politics: The Intellectual Contributions of Ernst B. Haas". Annual Review of Political Science, 8, 271-296.

Schattschneider, Elmer Eric (1960). The Semisoveriegn People: A Realist's View of Democracy in America. New York: Holt, Rinehart and Winston.

Schelling, Thomas (1960). The Strategy of Conflict. Cambridge: Harvard University Press. Sell, Susan (2003). Private Power, Public Law: The Globalization of Intellectual Property Rights. Cambridge: Cambridge University Press.

Skjaerseth, Jon Birger and Wettestad, Jorgen (2008). EU Emissions Trading: Initiation, Decision-making and Implementation. Aldershot: Ashgate.

Slaughter, Anne-Marie (2004). A New World Order. Princeton: Princeton University Press.

Smith, James (2006). Compliance bargaining in the WTO: Ecuador and the bananas dispute. In: Odell, John (ed.) Negotiating Trade: Developing Countries in the WTO and NAFTA. Cambridge: Cambridge University Press.

Smith, James and Tallberg, Jonas 2005. Compliance Bargaining in International Cooperation. Annual Meeting of the American Political Science Association. Washington D.C.

Spector, Bertram (2003). Deconstructing the Negotiations of Regime Dynamics. In: Spector, Bertram \& Zartman, I William editor, Getting It Done: Postagreement Negotiation and International Regimes Washington D.C.: United States Institute of Peace Press.

Spector, Bertram and Zartman, William (2003). Regimes and Negotiation: An Introduction. In: Spector, Bertram \& Zartman, William editor, Getting It Done: Postagreement Negotiation and International Regimes. Washington D.C.: United States Institute of Peace Press.

Stiglitz, Joseph (2006). Making Globalization Work. Camberwell: Allen Lane.

Stokke, Olav (2004). "Trade measures and climate compliance: institutional interplay between WTO and the Marrakesh Accords". International Environmental Agreements: politics, law, and economics, 4, 4: 339-357.

Susskind, Lawrence and Crump, Larry (eds.) 2008. Multiparty Negotiation, Los Angeles: Sage Publications.

Trumbore, Peter (1998). "Public Opinion as a Domestic Constraint in International Negotiations: Two-Level Games in the Anglo-Irish Peace Process". International Studies Quarterly, 42, 545-565.

Yin, Robert (2009). Case Study Research Design and Methods. London: Sage Publications. Young, Oran (1999). Regime Effectiveness: Taking Stock. In: Young, Oran (ed.) The Effectiveness of International Environmental Regimes. Cambridge: The MIT Press. 
Young, Oran (2011). Improving the Performance of the Climate Regime: Insights from Regime Analysis. In: Dryzek, John, Norgaard, Richard \& Schlosberg, David editor, The Oxford Handbook of Climate Change and Society. Oxford: Oxford University Press.

Young, Oran and Levy, Marc (1999). The Effectiveness of International Environmental Regimes. In: Young, Oran (ed.) The Effectiveness of International Environmental Regimes. Cambridge: The MIT Press.

Zartman, I William (1989). "Prenegotiation: Phases and functions". International Journal, 44, 2: 237-253.

Zartman, I William and Berman, Maureen (1982). The Practical Negotiator. New Haven: Yale University Press.

Zartman, William (2003). Negotiating the Rapids: The Dynamics of Regime Formation. In: Spector, Bertram \& Zartman, William editor, Getting It Done: Postagreement Negotiation and International Regimes. Washington D.C.: United States Institute of Peace Press. 